\title{
Article
}

\section{Oral Acid Load Down-Regulates Fibroblast Growth Factor 23}

\author{
Angela Vidal ${ }^{1,2}\left(\right.$, Carmen Pineda ${ }^{1,2}{ }^{\oplus}$, Ana I. Raya ${ }^{1,2}$, Rafael Rios ${ }^{1,2}$, Azahara Espartero ${ }^{1,2}$, \\ Juan R. Muñoz-Castañeda 2 (D), Mariano Rodriguez ${ }^{2}$, Escolastico Aguilera-Tejero ${ }^{1,2, *,+}$ and Ignacio Lopez ${ }^{1,2,+}$ \\ 1 Department of Animal Medicine and Surgery, University of Cordoba, Campus Universitario Rabanales, \\ 14014 Cordoba, Spain; v92vicaa@uco.es (A.V.); cpimart@hotmail.com (C.P.); ana.raya@uco.es (A.I.R.); \\ rafariosvaro@me.com (R.R.); azaharaespartero@hotmail.com (A.E.); 102lovii@uco.es (I.L.) \\ 2 Maimonides Biomedical Research Institute of Cordoba (IMIBIC), Reina Sofia University Hospital, \\ University of Cordoba, 14004 Cordoba, Spain; juanr.munoz.exts@juntadeandalucia.es (J.R.M.-C.); \\ marianorodriguezportillo@gmail.com (M.R.) \\ * Correspondence: eaguilera@uco.es \\ + These authors contributed equally to this work.
}

Citation: Vidal, A.; Pineda, C.; Raya, A.I.; Rios, R.; Espartero, A.; Muñoz-Castañeda, J.R.; Rodriguez, M.; Aguilera-Tejero, E.; Lopez, I. Oral Acid Load Down-Regulates Fibroblast Growth Factor 23. Nutrients 2022, 14, 1041. https:// doi.org/10.3390/nu14051041

Academic Editor: Ebba Nexø

Received: 26 January 2022

Accepted: 26 February 2022

Published: 28 February 2022

Publisher's Note: MDPI stays neutral with regard to jurisdictional claims in published maps and institutional affiliations.

Copyright: (C) 2022 by the authors. Licensee MDPI, Basel, Switzerland. This article is an open access article distributed under the terms and conditions of the Creative Commons Attribution (CC BY) license (https:// creativecommons.org/licenses/by/ $4.0 /)$.

\begin{abstract}
Increased dietary acid load has a negative impact on health, particularly when renal function is compromised. Fibroblast growth factor 23 (FGF23) is a bone-derived hormone that is elevated during renal failure. The relationship between metabolic acidosis and FGF23 remains unclear. To investigate the effect of dietary acid load on circulating levels of FGF23, rats with normal renal function and with a graded reduction in renal mass $(1 / 2 \mathrm{Nx}$ and $5 / 6 \mathrm{Nx})$ received oral $\mathrm{NH}_{4} \mathrm{Cl}$ for 1 month. Acid intake resulted in a consistent decrease of plasma FGF23 concentrations in all study groups when compared with their non-acidotic control: $239.3 \pm 13.5 \mathrm{vs} .295 .0 \pm 15.8 \mathrm{pg} / \mathrm{mL}$ (intact), $346.4 \pm 19.7$ vs. $522.6 \pm 29.3 \mathrm{pg} / \mathrm{mL}(1 / 2 \mathrm{Nx})$ and $988.0 \pm 125.5$ vs. $2549.4 \pm 469.7 \mathrm{pg} / \mathrm{mL}$ (5/6 Nx). Acidosis also decreased plasma PTH in all groups, $96.5 \pm 22.3$ vs. $107.3 \pm 19.1 \mathrm{pg} / \mathrm{mL}$, $113.1 \pm 17.3$ vs. $185.8 \pm 22.2 \mathrm{pg} / \mathrm{mL}$ and $504.9 \pm 75.7$ vs. $1255.4 \pm 181.1 \mathrm{pg} / \mathrm{mL}$. FGF23 showed a strong positive correlation with PTH $(r=0.877, p<0.0001)$ and further studies demonstrated that acidosis did not influence plasma FGF23 concentrations in parathyroidectomized rats, $190.0 \pm 31.6 \mathrm{vs}$. $215 \pm 25.6 \mathrm{pg} / \mathrm{mL}$. In conclusion, plasma concentrations of FGF23 are consistently decreased in rats with metabolic acidosis secondary to increased acid intake, both in animals with intact renal function and with decreased renal function. The in vivo effect of metabolic acidosis on FGF23 appears to be related to the simultaneous decrease in PTH.
\end{abstract}

Keywords: acid intake; FGF23; PTH; kidney

\section{Introduction}

Nutrient intake plays a major role in the maintenance of acid-base homeostasis [1]. An excessive dietary acid load may lead to metabolic acidosis, particularly in individuals with chronic kidney disease (CKD) because the failing kidney is not able to produce the amount of bicarbonate required to buffer acid production resulting from diet and metabolism [2-4]. Chronic metabolic acidosis is thought to represent a major factor in the progression of CKD [5] and is generally associated with higher mortality risk [6].

Fibroblast growth factor 23 (FGF23) is a hormone secreted by osteocytes/osteoblasts that is involved in the regulation of mineral metabolism [7]. The main target organ for FGF23 is the kidney, where FGF23 increases urinary excretion of phosphate $(\mathrm{P})$ and decreases the synthesis of calcitriol [8].

Synthesis and secretion of FGF23 are regulated mainly by dietary P. In fact, an increased P intake is thought to be the most important stimulus for FGF23 secretion $[9,10]$. In addition, FGF23 production is under hormonal control by calcitriol [11,12] and by parathyroid hormone (PTH), which stimulates FGF23 secretion [13]. Moreover, inflammation [14], iron deficiency [15] and high caloric intake [16] have been reported to increase FGF23 production. 
Elevated levels of FGF23 are usually found in patients with renal failure, due to $P$ retention and hyperphosphatemia, and FGF23 has been reported as a risk factor of cardiovascular mortality both in patients with CKD [17] and in healthy individuals [18,19].

The connection between FGF23 and metabolic acidosis is unclear. How acidosis affects FGF23 production should be known because it may influence dietary recommendations for the general population and, particularly, for persons with reduced renal function. In vitro studies have shown that acidosis stimulates FGF23 production by neonatal mouse bone $[20,21]$. However, to our knowledge, in vivo studies specifically designed to investigate the effect of metabolic acidosis on FGF23 have not been conducted. Interestingly, the few collateral data that have been reported from in vivo studies, that were originally designed for other purposes, do not support a stimulatory effect of acidosis on FGF23 [22-24]. Thus, it is necessary to clarify the relationship between metabolic acidosis and increased FGF23 concentrations.

The aim of this work was to test the hypothesis that, as previously shown in vitro, metabolic acidosis also up-regulates circulating levels of FGF23 in vivo. To this purpose, we investigated the influence of increased acid intake (in the form of $\mathrm{NH}_{4} \mathrm{Cl}$ supplied with drinking water) on FGF23 in healthy rats and in rats with several degrees of impairment in renal function. In addition, in vitro studies were conducted in UMR 106 cells cultured at different $\mathrm{pH}$.

\section{Materials and Methods}

\subsection{Ethics}

Experimental protocols were reviewed and approved by the Ethics Committee for Animal Research of the University of Cordoba and by Junta de Andalucia (Spain) (Ethical Code Number 30/10/2017/148, dated 8 November 2017). All the studies were carried out in accordance with the approved guidelines.

\subsection{In Vivo Experiments}

\subsubsection{Animals and Diets}

Two months old female Wistar rats, provided by the Animal Housing Facilities of the University of Cordoba (Cordoba, Spain), were used in the studies.

Dietary modification, including changes in $\mathrm{P}$ and fat content, was used as a part of the treatment. Three diets were used in the experiments: a standard diet (Altromin C 1090-10, AltrominSpezialfutter $\mathrm{GmbH}$, Lage, Germany) with either a normal (0.6\%) or high (1.2\%) P concentration, and a diet with high-fat (HF) content and $0.6 \% \mathrm{P}$ concentration (Altromin $\mathrm{C}$ 1090-60, AltrominSpezialfutter $\mathrm{GmbH}$, Germany). These diets contained normal amounts of calcium (Ca) and vitamin D: $0.6 \%$ of Ca and $500 \mathrm{IU} / \mathrm{g}$ of vitamin D. Daily food intake was recorded for each rat by averaging the amount of food eaten every week.

\subsubsection{Generation of Kidney Disease}

Renal function was reduced by partial removal of renal mass and by dietary changes (increasing fat and P intake). For ablation of renal mass, two nephrectomy (Nx) procedures were carried out: 1/2 Nx and 5/6 Nx. Before performing surgery, rats were anesthetized using inhaled isoflurane (Isovet, Braun, Barcelona, Spain). For $1 / 2 \mathrm{Nx}$, the right kidney was exposed and removed. For $5 / 6 \mathrm{Nx}$, it was performed in two steps. In the first step, the left kidney was exposed, and the two poles (2/3 of renal mass) were ablated. After 1 week of recovery, in the second step, the animal was reanesthetized and the right kidney was excised, as described above. Fentanyl, $0.2 \mathrm{mg} / \mathrm{kg}$, ip (Fentanest, Kern Pharma, Barcelona, Spain) was used as an analgesic agent. Rats subjected to $1 / 2 \mathrm{Nx}$ were fed an HF diet to accelerate the deterioration of renal function induced by heminephrectomy.

\subsubsection{Parathyroidectomy}

A selective parathyroidectomy (PTX) was performed, as previously reported, with the aid of a dissecting microscope [13]. Briefly, with the rat under general anesthesia 
(inhaled isofluorane), the skin on the ventral part of the neck was incised, the thyroid was exposed, and the parathyroid glands were identified, dissected and ablated. Hemorrhage was prevented by electrocautery.

\subsubsection{Induction of Acidosis}

Metabolic acidosis was induced in rats with intact renal function and in $1 / 2 \mathrm{Nx}$ rats by oral administration of a $\mathrm{NH}_{4} \mathrm{Cl}$ solution, $1 \% \mathrm{NH}_{4} \mathrm{Cl}$ (Scharlau, Scharlab, Barcelona, Spain) dissolved in water, instead of normal drinking water. In $5 / 6 \mathrm{Nx}$ rats, the $\mathrm{NH}_{4} \mathrm{Cl}$ concentration was reduced to $0.75 \%$. Control (non-acidotic) rats received tap water. In all groups, $0.1 \%$ sodium saccharin (Scharlau, Scharlab, Barcelona, Spain) was added to drinking water to improve its palatability.

\subsubsection{Experimental Design}

\section{(a) Acidosis with intact parathyroid function}

Rats were randomly allotted to 6 groups ( $n=9$ per group) using specific software (Research Randomizer). The number of rats per group was calculated based on the dispersion observed when measuring the parameters under investigation in previous studies by our laboratory, and assuming a 95\% confidence level. Three groups (Groups 1, 3 and 5) included rats with normal acid-base balance and 3 groups (Groups 2, 4, and 6) included rats with acidosis (Figure S1):

Group 1 (Control), rats with an intact renal function that were fed a standard diet $(0.6 \% \mathrm{P})$.

Group 2 (Control+Acid) was similar to Group 1, but the rats received $\mathrm{NH}_{4} \mathrm{Cl}$ to induce metabolic acidosis.

Group $3(1 / 2 \mathrm{Nx}), 1 / 2 \mathrm{Nx}$ rats fed HF diet.

Group $4(1 / 2 \mathrm{Nx}+\mathrm{Acid})$ was similar to Group 3, with the addition of $\mathrm{NH}_{4} \mathrm{Cl}$ to induce chronic metabolic acidosis.

Group $5(5 / 6 \mathrm{Nx})$, rats with $5 / 6 \mathrm{Nx}$ were fed a standard diet with high $\mathrm{P}(1.2 \% \mathrm{P})$.

Group $6(5 / 6 \mathrm{Nx}+\mathrm{Acid})$ was similar to Group 5 plus $\mathrm{NH}_{4} \mathrm{Cl}$ to induce chronic metabolic acidosis.

To confirm an even distribution of rats between the different experimental groups, rats were weighed before commencing the experiments. No significant difference in the body weight of the study groups was found (Group $1=219.7 \pm 5.2 \mathrm{~g}$, Group $2=226.4 \pm 5.8 \mathrm{~g}$, Group $3=221.3 \pm 2.3 \mathrm{~g}$, Group $4=216.6 \pm 2.2 \mathrm{~g}$, Group $5=226.7 \pm 3.0 \mathrm{~g}$ and Group $6=227.5 \pm 2.6 \mathrm{~g}$ ).

Rats received the treatments for 30 days and at the end of the experiments were sacrificed by exsanguination under general anesthesia (inhaled isoflurane) to obtain blood samples (from the abdominal aorta). For twenty-four hours, urine samples were collected for the 3 days prior to sacrifice by placing the rats in metabolic cages.

(b) Acidosis with parathyroidectomy

Rats with intact renal function fed a standard diet (Altromin C 1090-10, AltrominSpezialfutter GmbH, Lage, Germany) were subjected to PTX, as described above. Twentyfour hours after parathyroidectomy, rats were allotted to two groups: PTX $(n=6)$ and PTX+Acid $(n=8)$. PTX (non-acidotic) rats received tap water, while PTX+Acid received a $1 \% \mathrm{NH}_{4} \mathrm{Cl}$ solution instead of drinking water, as described above. Both groups of rats were euthanized after 30 days of treatment. Blood and urine collections were performed as described above.

\subsubsection{Blood and Urine Chemistries}

Arterial blood gas analysis and ionized calcium $\left(\mathrm{Ca}^{2+}\right)$ measurements were performed immediately after blood collection using selective electrodes (RapidLab, Siemens Healthcare $\mathrm{GmbH}$, Germany). Afterwards, plasma was separated by centrifugation and stored at $-20{ }^{\circ} \mathrm{C}$ until assayed. Plasma concentrations of $\mathrm{P}$, creatinine and urea, and urine $\mathrm{Ca}$ 
(total Ca) and P were measured by spectrophotometry (Biosystems SA, Barcelona, Spain). Urine $\mathrm{pH}$ was measured with $\mathrm{pH}$ indicator strips (Scharlau, Scharlab SL, Barcelona, Spain). ELISA tests were used to quantify intact FGF23, iFGF23 (Kainos Laboratories, Tokyo, Japan), carboxy-terminal FGF23, cFGF23 (Immutopics Inc., Quidel Corporation, OH, USA) and PTH (Immutopics Inc., Quidel Corporation, OH, USA). Radioimmunoassay (Immunodiagnostic Systems Ltd., Boldon, UK) was used in plasma samples to determine 1,25-dihydroxyvitamin D (calcitriol).

\subsection{In Vitro Experiments \\ 2.3.1. Cell Culture}

Rat osteosarcoma cells UMR 106 (ATCC, Manassas, VA, USA) were cultured in Dulbecco's modified Eagle's medium (DMEM) (Sigma-Aldrich, St. Louis, MO, USA) supplemented with 10\% fetal bovine serum (FBS) (Biowest, Riverside, MO, USA). Cells were seeded in 6 wells plates with 10,000 cells $/ \mathrm{cm}^{2}$ and maintained in DMEM up to $90 \%$ confluence. FGF23 production was stimulated by adding calcitriol $\left(10^{-8} \mathrm{M}\right)$ (Kern pharma, Barcelona, Spain), as previously reported [25]. Two groups of experiments were performed to study the effect of acidosis on FGF23 production: short-term and longer-term experiments. Short-term experiments were carried out in cells that had grown in a medium with normal (7.4) $\mathrm{pH}$ and were briefly exposed (for $24 \mathrm{~h}$ ) to a low (7.2) $\mathrm{pH}$ medium. The $\mathrm{pH}$ of the culture medium was reduced by adding $\mathrm{HCl}$. In longer-term experiments, cells were incubated until they reached confluence (for 6 days) in either DMEM with normal pH (7.4) or DMEM with low $\mathrm{pH}$ (7.2).

\subsubsection{RNA Extraction and Real-Time Reverse Transcription-Polymerase Chain} Reaction (RT-PCR)

Total RNA was isolated using the TRIzol reagent protocol (Invitrogen, Thermo Fisher Scientific, Walthan, MA, USA). The sequence of primers used for RT-PCR is shown in Table S1. Quantification was done using the QuantiTect SYBR Green RT-PCR kit (Qiagen $\mathrm{GmbH}$, Hilden, Germany) for $50 \mathrm{ng}$ of RNA and $1 \mu \mathrm{L}$ of primer. The mRNA expression was analyzed in the Light Cycler thermal cycler system (Roche Diagnostics, Indianapolis, IN, USA) and the relative expression of the target genes was determined using the $2^{-\Delta \Delta C t}$ method.

\subsection{Statistical Analysis}

Statistical analysis was conducted with the software Prism/GraphPad v6. Values were reported as mean \pm standard error (SE). To compare the difference of the means of 3 or more groups, ANOVA, followed by the Fisher LSD test as a post-hoc procedure was used. When only 2 groups were involved, an intergroup comparison was performed by $t$-tests. Pearson correlation coefficients were used to estimate and assess the strength of associations. A $p<0.05$ was considered significant.

\section{Results}

\subsection{In Vivo Studies}

\subsubsection{Renal Function}

Plasma creatinine and urea concentrations in the study groups are shown in Table 1. Acidosis tended to decrease plasma creatinine, but significant differences with the nonacidotic controls were only observed in $5 / 6 \mathrm{Nx}$ rats.

\subsubsection{Acid-Base Balance}

As intended, mild metabolic acidosis was achieved in rats with normal renal function and in $1 / 2 \mathrm{Nx}$ rats. Thus, a decrease in blood $\mathrm{pH}$ was only observed in 5/6 Nx rats, $7.07 \pm 0.07$ vs. $7.42 \pm 0.02$. However, a significant reduction in urine $\mathrm{pH}$ was detected in all acidotic groups (Figure 1). Changes in plasma bicarbonate were only apparent in acidotic $5 / 6 \mathrm{Nx}$ rats, while the anion gap was increased in the non-acidotic 5/6 Nx group (Table 2). 
Table 1. Plasma creatinine and urea concentrations in the six experimental groups at the end of the experiment.

\begin{tabular}{lcc}
\hline & Creatinine $(\mathbf{m g} / \mathbf{d L})$ & Urea $(\mathbf{m g} / \mathbf{d L})$ \\
\hline Control & $0.66 \pm 0.01$ & $30.2 \pm 1.2$ \\
Control+Acid & $0.63 \pm 0.01$ & $27.0 \pm 0.8$ \\
$1 / 2 \mathrm{Nx}$ & $0.80 \pm 0.02^{\mathrm{a}}$ & $39.1 \pm 1.8^{\mathrm{a}}$ \\
$1 / 2 \mathrm{Nx}+$ Acid & $0.76 \pm 0.01^{\mathrm{a}}$ & $34.1 \pm 1.5$ \\
$5 / 6 \mathrm{Nx}$ & $1.12 \pm 0.05^{\mathrm{a}}$ & $70.3 \pm 7.7^{\mathrm{a}}$ \\
$5 / 6 \mathrm{Nx}+$ Acid & $0.94 \pm 0.03^{\mathrm{a}}$ & $82.1 \pm 10.1^{\mathrm{a}}$ \\
\hline
\end{tabular}

Letters $\left({ }^{a}\right)$ indicate significant differences $(p<0.05)$ vs. control group. Asterisks $\left(^{*}\right)$ indicate differences vs. its non-acidotic counterpart $(p<0.05)$. Values are means \pm SE. Control, rats with intact renal function fed a standard diet. Control+Acid, rats with intact renal function fed a standard diet and induced metabolic acidosis. $1 / 2 \mathrm{Nx}$ heminephrectomized rats fed a high-fat diet. $1 / 2 \mathrm{Nx}+$ Acid, heminephrectomized rats fed a high-fat diet and induced metabolic acidosis. $5 / 6 \mathrm{Nx}$, rats subjected to $5 / 6$ nephrectomy fed a high phosphorous diet. $5 / 6 \mathrm{Nx}+\mathrm{Acid}$, rats subjected to $5 / 6$ nephrectomy fed a high phosphorous diet and induced metabolic acidosis.

a)

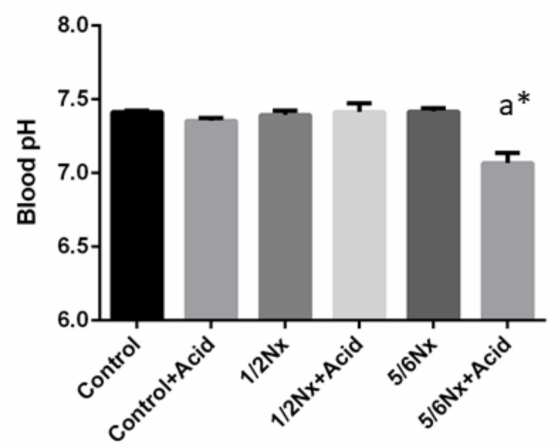

b)

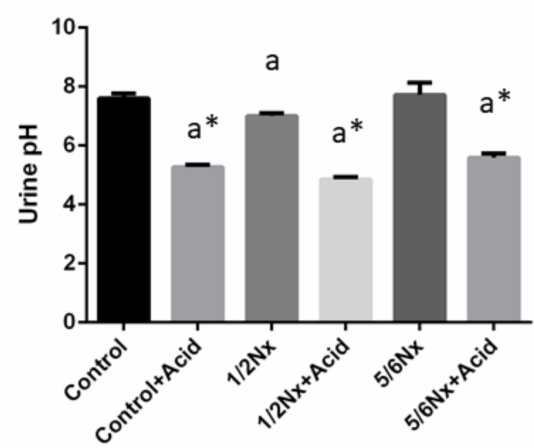

Figure 1. Acid-base parameters. (a) Blood $\mathrm{pH}$, and (b) urine $\mathrm{pH}$ in rats ( $n=9$ per group) with normal (control) and reduced $(1 / 2 \mathrm{Nx}$ and $5 / 6 \mathrm{Nx})$ renal function without and with (+Acid) metabolic acidosis. ${ }^{a} p<0.05$ vs. control; ${ }^{*} p<0.05$ vs. its non-acidotic counterpart.

Table 2. Blood parameters related to acid-base balance in the six experimental groups at the end of the experiment.

\begin{tabular}{lcc}
\hline & Bicarbonate $(\mathbf{m m o l} / \mathrm{L})$ & Anion Gap $(\mathbf{m m o l} / \mathrm{L})$ \\
\hline Control & $25.9 \pm 0.5$ & $11.4 \pm 0.4$ \\
Control+Acid & $24.7 \pm 0.7$ & $10.6 \pm 0.6$ \\
$1 / 2 \mathrm{Nx}$ & $24.9 \pm 0.3$ & $10.9 \pm 0.6$ \\
$1 / 2 \mathrm{Nx}+$ Acid & $23.7 \pm 0.6$ & $10.6 \pm 0.4$ \\
$5 / 6 \mathrm{Nx}$ & $24.2 \pm 1.1$ & $20.3 \pm 2.8^{\mathrm{a}}$ \\
$5 / 6 \mathrm{Nx}+$ Acid & $12.6 \pm 2.9^{\mathrm{a} *}$ & $15.6 \pm 1.0^{*}$ \\
\hline
\end{tabular}

Letters $\left(^{a}\right)$ indicate significant differences $(p<0.05)$ vs. control group. Asterisks $\left(^{*}\right)$ indicate differences vs. its non-acidotic counterpart $(p<0.05)$. Values are means \pm SE. Control, rats with intact renal function fed a standard diet. Control+Acid, rats with intact renal function fed a standard diet and induced metabolic acidosis. 1/2 Nx, heminephrectomized rats fed a high-fat diet. $1 / 2 \mathrm{Nx}+\mathrm{Acid}$, heminephrectomized rats fed a high-fat diet and induced metabolic acidosis. 5/6 Nx, rats subjected to 5/6 nephrectomy fed a high phosphorous diet. 5/6 Nx+Acid, rats subjected to $5 / 6$ nephrectomy fed a high phosphorous diet and induced metabolic acidosis.

\subsubsection{Mineral Metabolism}

Plasma P concentrations tended to increase with the reduction in renal function and acidosis further increased plasma $\mathrm{P}$ in $5 / 6 \mathrm{Nx}$ rats, $7.6 \pm 0.7$ vs. $6.0 \pm 0.4 \mathrm{mg} / \mathrm{dL}$. Since acidotic rats decreased food intake and, consequently $\mathrm{P}$ intake, when compared with nonacidotic controls (Table S2), urinary excretion of $\mathrm{P}$ was expressed as the ratio daily urinary $\mathrm{P}$ excretion ( $\mathrm{mg} /$ day)/daily $\mathrm{P}$ ingestion $(\mathrm{mg} /$ day). Urinary excretion of $\mathrm{P}$ increased in rats with reduced renal function, particularly in $1 / 2 \mathrm{Nx}$ rats. Acidosis resulted in a further increase in urinary $\mathrm{P}$ excretion in all groups and significant differences were observed in rats with intact renal function, $0.37 \pm 0.02$ vs. $0.30 \pm 0.01$ (Figure 2). 
a)

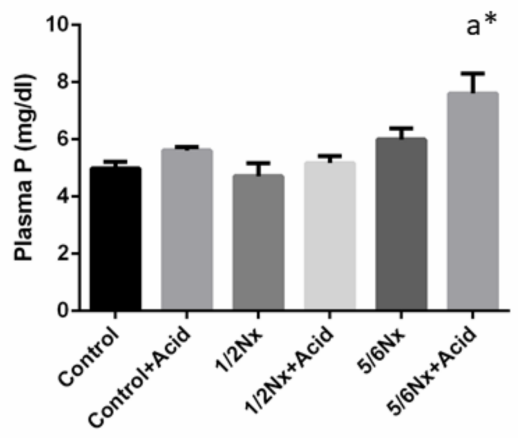

c)

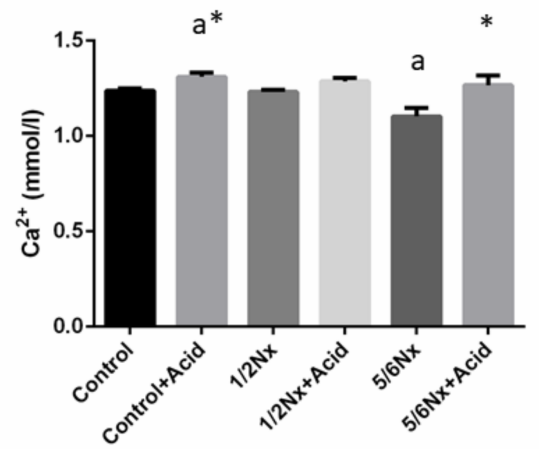

b)

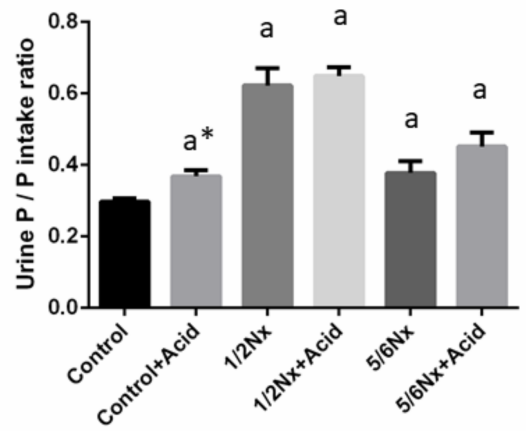

d)

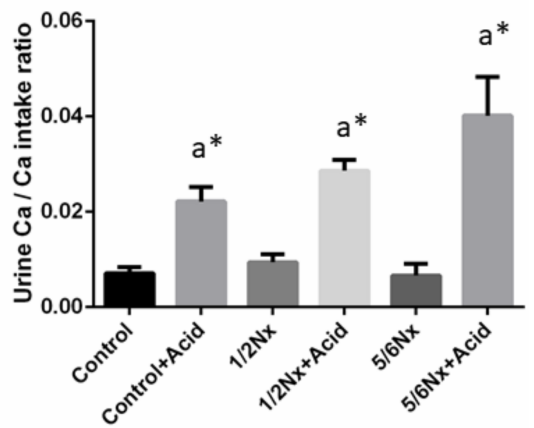

Figure 2. Plasma concentrations and urinary excretion of phosphate and calcium. (a) Plasma phosphate, $\mathrm{P},(\mathbf{b})$ urinary excretion of $\mathrm{P},(\mathbf{c})$ plasma ionized calcium, $\mathrm{Ca}^{2+}$, and (d) urinary excretion of $\mathrm{Ca}$ in rats ( $n=9$ per group) with normal (control) and reduced $(1 / 2 \mathrm{Nx}$ and $5 / 6 \mathrm{Nx}$ ) renal function without and with (+Acid) metabolic acidosis. ${ }^{a} p<0.05$ vs. control. ${ }^{*} p<0.05$ vs. its non-acidotic counterpart.

Blood $\mathrm{Ca}^{2+}$ concentrations did not change in $1 / 2 \mathrm{Nx}$ rats but were significantly reduced in $5 / 6 \mathrm{Nx}$ rats, $1.10 \pm 0.04$ vs. $1.24 \pm 0.01 \mathrm{mmol} / \mathrm{L}$ in controls with normal renal function. Acidosis resulted in increases in $\mathrm{Ca}^{2+}$ that were significant both in controls, $1.31 \pm 0.02 \mathrm{mmol} / \mathrm{L}$ and in 5/6 Nx, $1.27 \pm 0.05 \mathrm{mmol} / \mathrm{L}$. Urinary excretion of Ca was consistently increased in all acidosis groups (Figure 2).

Plasma calcitriol concentrations were not substantially altered by the reduction in renal function. Acidosis tended to decrease plasma calcitriol and significant differences were recorded in 5/6 Nx rats, $27.4 \pm 6.1$ vs. $59.4 \pm 7.7 \mathrm{pg} / \mathrm{mL}$ (Figure 3).

a)

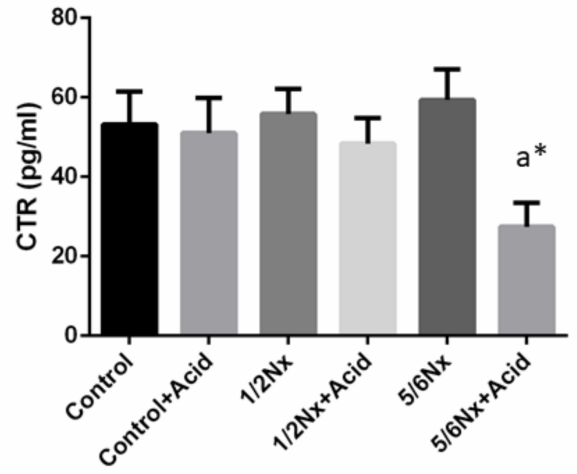

b)

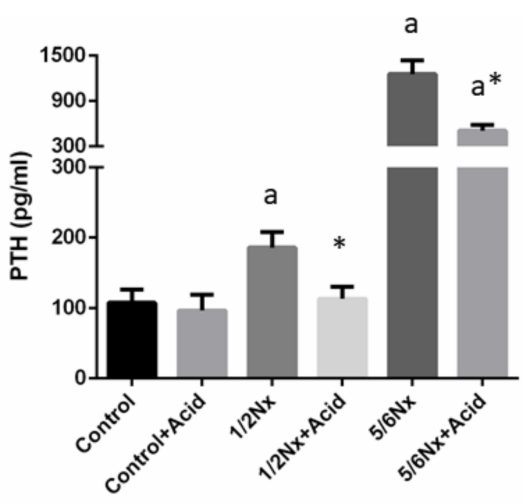

Figure 3. Plasma concentrations of calcitriol and parathyroid hormone. (a) Calcitriol (CTR) and (b) parathyroid hormone (PTH) in rats ( $n=9$ per group) with normal (control) and reduced $(1 / 2 \mathrm{Nx}$ and $5 / 6 \mathrm{Nx}$ ) renal function without and with (+Acid) metabolic acidosis. ${ }^{\mathrm{a}} p<0.05$ vs. control; $* p<0.05$ vs. its non-acidotic counterpart.

Circulating PTH concentrations increased progressively with the deterioration of renal function, from $107.3 \pm 19.1$ in rats with normal renal function to $1255.4 \pm 181.1 \mathrm{pg} / \mathrm{mL}$ in 
5/6 Nx rats. Acidosis resulted in a decrease in plasma PTH in all groups, $96.5 \pm 22.3$ vs. $107.3 \pm 19.1 \mathrm{pg} / \mathrm{mL}, 113.1 \pm 17.3$ vs. $185.8 \pm 22.2 \mathrm{pg} / \mathrm{mL}$ and $504.9 \pm 75.7$ vs. $1255.4 \pm 181.1 \mathrm{pg} / \mathrm{mL}$, although significant differences were only observed in rats with reduced renal function (Figure 3 ).

Plasma concentrations of iFGF23 increased progressively in the study groups as a reflection of the decline in renal function, from $295.0 \pm 16.8 \mathrm{pg} / \mathrm{mL}$, in rats with intact renal function to $2549.4 \pm 469.7 \mathrm{pg} / \mathrm{mL}$ in $5 / 6 \mathrm{Nx}$ rats. Acidosis resulted in a consistent decrease of iFGF23 in all study groups when compared with their non-acidotic control: $239.3 \pm 13.5$ vs. $295.0 \pm 15.8 \mathrm{pg} / \mathrm{mL}$ (intact renal function), $346.4 \pm 19.7$ vs. $522.6 \pm 29.3 \mathrm{pg} / \mathrm{mL}$ $(1 / 2 \mathrm{Nx})$ and $988.0 \pm 125.5$ vs. $2549.4 \pm 469.7 \mathrm{pg} / \mathrm{mL}$ (5/6 Nx) (Figure 4). Circulating levels of cFGF23 were increased with deteriorated renal function and were also significantly reduced in acidotic rats with normal renal function, $115.2 \pm 7.3 \mathrm{vs} .181 .0 \pm 17.5 \mathrm{pg} / \mathrm{mL}$, and in $1 / 2 \mathrm{Nx}$ rats, $201.3 \pm 17.7$ vs. $287.2 \pm 19.9 \mathrm{pg} / \mathrm{mL}$ but not in $5 / 6 \mathrm{Nx}$ rats, $959.4 \pm 600.5$ vs. $874.7 \pm 187.0 \mathrm{pg} / \mathrm{mL}$ (Figure 4 ). However, the $5 / 6 \mathrm{Nx}$ results were influenced by an outlier in the acidotic group that had an extremely high cFGF23 concentration $(2751.5 \mathrm{pg} / \mathrm{mL})$. When the data from this rat was not included in the statistical analysis, a decrease in cFGF23 was also observed in acidotic 5/ $6 \mathrm{Nx}$ rats, $362.0 \pm 85.91$ vs. $874.7 \pm 187.0(p=0.142)$.

a)

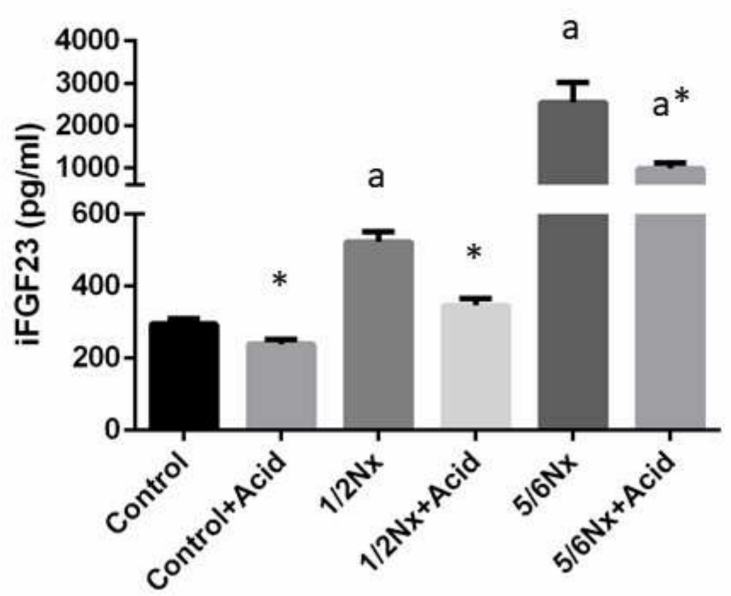

b)

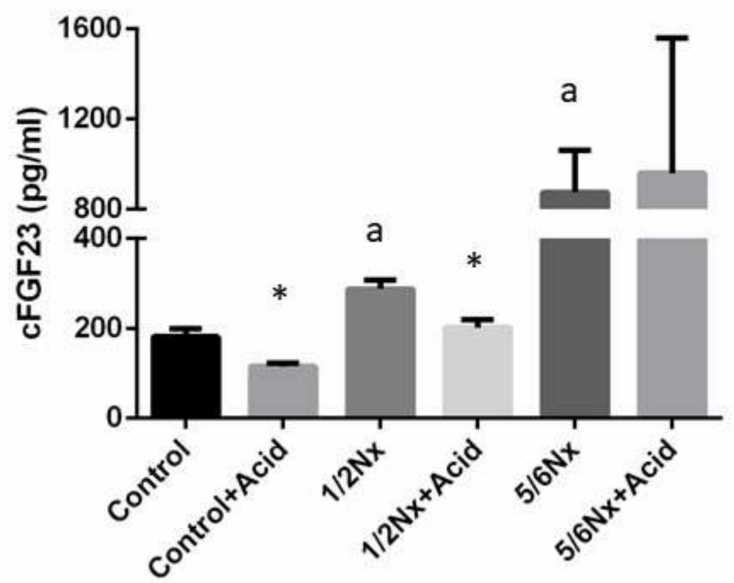

Figure 4. Plasma concentrations of fibroblast growth factor 23 (FGF23). (a) Intact FGF23, iFGF23, and (b) carboxy-terminal FGF23, cFGF23, in rats ( $n=9$ per group) with normal (control) and reduced $(1 / 2 \mathrm{Nx}$ and $5 / 6 \mathrm{Nx})$ renal function without and with (+Acid) metabolic acidosis. ${ }^{\mathrm{a}} p<0.05$ vs. control; ${ }^{*} p<0.05$ vs. its non-acidotic counterpart.

As shown in Figure 5, iFGF23 concentrations were weakly correlated with plasma P concentrations $(\mathrm{r}=0.372, p=0.006)$ but this direct correlation was a likely consequence of the simultaneous increases of $\mathrm{P}$ and FGF23 secondary to a deterioration of renal function and may not reflect the effect of acidosis on FGF23. By contrast, iFGF23 showed a strong positive correlation with plasma PTH concentrations $(\mathrm{r}=0.877, p<0.0001)$. No correlation was found between iFGF23 and calcitriol concentrations $(\mathrm{r}=-0.014, p=0.928)$. The correlation study yielded similar results when it was carried out using cFGF23 data (Figure S2).

To further explore the role of PTH in the acidosis-induced decrease in FGF23, in vivo experiments were repeated in a subset of parathyroidectomized (PTX) rats with normal renal function. In these rats, acid ingestion resulted in significant decreases in plasma $\mathrm{pH}, 7.27 \pm 0.02$ vs. $7.40 \pm 0.01$, and bicarbonate, $16.7 \pm 1.0$ vs. $24.6 \pm 0.5 \mathrm{mmol} / \mathrm{L}$. However, iFGF23 did not change in PTX rats subjected to acidosis, $190.0 \pm 31.6$ vs. $215.9 \pm 25.6 \mathrm{pg} / \mathrm{mL}$ (Table 3$)$. 
a)

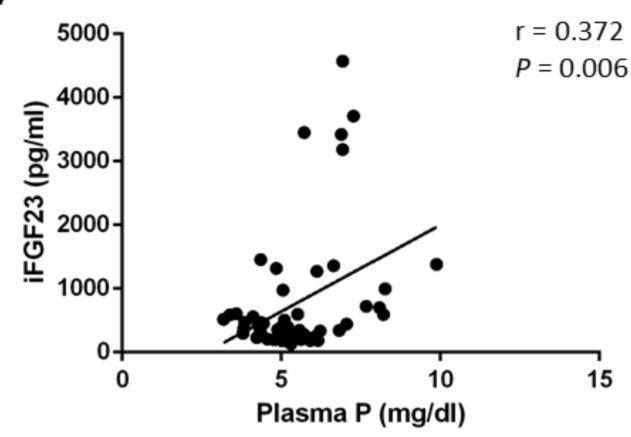

b)

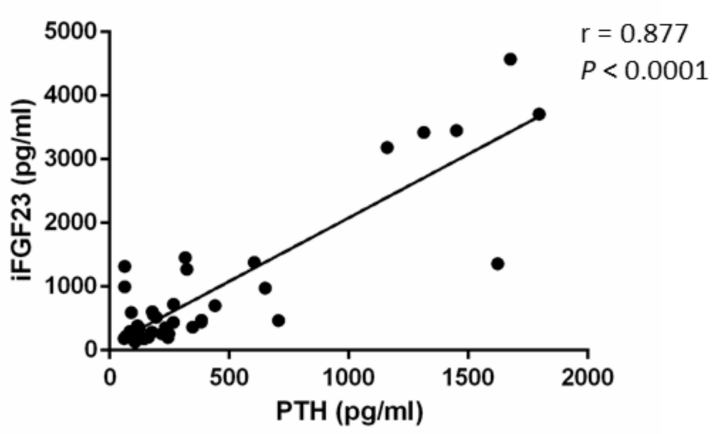

c)

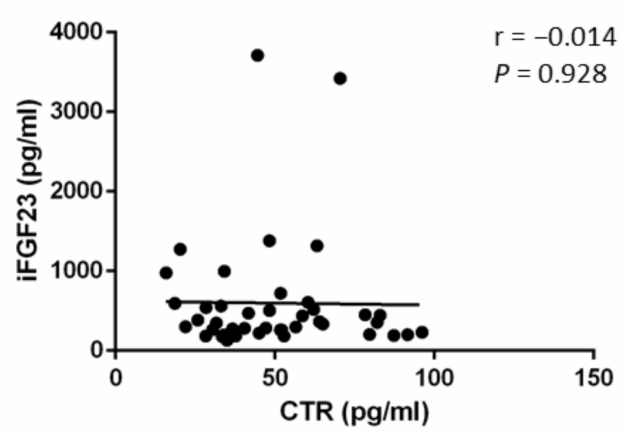

Figure 5. iFGF23 correlations. Correlation between plasma concentrations of intact fibroblast growth factor 23 (iFGF23) and: (a) plasma phosphate, P, (b) plasma parathyroid hormone, PTH and (c) plasma calcitriol, CTR, concentrations.

Table 3. Blood parameters related to acid-base balance and plasma intact fibroblast growth factor 23 (iFGF23) concentrations in parathyroidectomized rats.

\begin{tabular}{lccc}
\hline & pH & $\begin{array}{c}\text { Bicarbonate } \\
(\mathbf{m m o l} / \mathrm{L})\end{array}$ & iFGF23 (pg/mL) \\
\hline PTX & $7.40 \pm 0.01$ & $24.6 \pm 0.5$ & $215.9 \pm 25.6$ \\
PTX+Acid & $7.27 \pm 0.02{ }^{*}$ & $16.7 \pm 1.0 *$ & $190.0 \pm 31.6$ \\
\hline
\end{tabular}

Asterisks $\left(^{*}\right)$ indicate differences vs. non-acidotic group $(p<0.05)$. Values are means \pm SE. PTX, non-acidotic parathyroidectomized rats. PTX+Acid, parathyroidectomized rats with induced metabolic acidosis.

\subsection{In Vitro Studies}

UMR 106 cells increased FGF23 mRNA expression (arbitrary units vs. tbp) when exposed to acidic medium both short-term $(24 \mathrm{~h}), 1.23 \pm 0.07 \mathrm{vs} .1 .01 \pm 0.03(p=0.004)$ and longer-term ( 6 days) $1.21 \pm 0.08$ vs. $1.01 \pm 0.04(p=0.032)$.

\section{Discussion}

This study aimed to elucidate the effect of increased acid intake on circulating FGF23 concentrations. Our results demonstrate that metabolic acidosis was associated with lower plasma FGF23 concentrations. This effect was very consistent and reproducible along a scale of renal function (from intact to markedly impaired). The decrease in FGF23 in chronic metabolic acidosis was associated with a simultaneous decrease in PTH and was not observed after PTX.

Increased levels of FGF23 and metabolic acidosis are detrimental to health, and they contribute to the progression of renal disease and survival [5,17]. Thus, the present study was designed to investigate the effect of metabolic acidosis on plasma FGF23 concentrations in healthy rats and in rats with impaired renal function. The reduction in renal function was graded to simulate clinical situations of CKD stages 2-3 and stage 4. A moderate reduction in renal function was achieved by a heminephrectomy combined with feeding 
high-fat diets. This model, which has been used previously by our group [26], combines ablation of renal mass and subtle damage to the remnant kidney, which mimics human CKD associated with metabolic syndrome. The 5/6 Nx combined with a high P diet is the most common procedure for the induction of severe kidney disease in rats [27]. Metabolic acidosis was achieved by oral administration of $\mathrm{NH}_{4} \mathrm{Cl}$, which is also a universal method to produce acidosis in rodents [28]. Many studies of acidosis in rats have induced severe acidosis that may not be translated to patients with CKD. Thus, we aimed to achieve both mild acidosis (in rats with intact renal function and with $1 / 2 \mathrm{Nx}$ ) and severe acidosis (in $5 / 6$ Nx rats).

Previous work has shown that in vitro, metabolic acidosis stimulates FGF23 production by neonatal mouse calvaria cells $[20,21]$. Our results confirm these findings using a different cell line, UMR 106. A recent study also demonstrates a stimulatory action of weak acids (e.g., lactate) on FGF23 production in vitro, which is attributed to both a $\mathrm{pH}$-mediated effect and an inflammation-mediated effect [29]. Typically, in vitro experiments are of short duration (e.g., $24 \mathrm{~h}$ ) and this might account for the difference between in vitro and in vivo studies. However, our data demonstrate that the influence of acidosis on FGF23 in vitro is not restricted to short-term experiments $(24 \mathrm{~h})$ but it can also be demonstrated in longer-term (6 days) experiments. Taken together, these results would indicate that the direct effect of acidosis on bone is to stimulate FGF23 secretion. It is interesting to point out that acidosis has also been shown to stimulate the production of another phosphaturic hormone, PTH [30].

However, based on our results, metabolic acidosis secondary to increased acid intake resulted in a consistent decrease in plasma FGF23 concentrations. Although to our knowledge, this is the first report documenting a decrease in FGF23 as a consequence of acidosis - there are some data in the literature that point in the same direction.

In a large cross-sectional study involving 980 CKD patients, Khairallah et al. investigated the relationship between circulating FGF23 concentrations and acid-base balance [24]. They did not find an association between FGF23 and either the potential acid load or bicarbonate, however, FGF23 tended to be lower in patients with an increased net acid excretion, although the differences were not significant when data were adjusted for clinical factors (estimated glomerular filtration rate, 24-h urine albumin, diabetes, etc.). It is interesting to note that in this study, cFGF23 was measured and, according to our data, advanced renal disease may tamper the effect of acidosis on cFGF23.

In a study designed to investigate the effect of acidosis on vascular calcification, Leibrock et al. found that $\mathrm{NH}_{4} \mathrm{Cl}$ administration decreased iFGF23 in klotho-deficient mice but not in wild-type mice. These changes were observed only in iFGF23, but not in cFGF23 [22].

In CKD patients with mild metabolic acidosis (plasma bicarbonate $20-24 \mathrm{mEq} / \mathrm{L}$ ) Chen et al. administered increasing doses of oral sodium bicarbonate for 6 weeks. Contrary to their expectations, these authors found an increase in plasma cFGF23 concentrations after bicarbonate treatment and concluded that it was unclear whether the increase in cFGF23 would be related to the alkalosis induced by bicarbonate [23].

Given the discrepancy between in vitro and in vivo studies, it is likely that the in vivo effect of acidosis may be related to changes in other parameters of mineral metabolism that regulate FGF23 production by bone cells. The main factors that impact FGF23 synthesis and secretion are $\mathrm{P}$, calcitriol and PTH [9-13].

The most important biological action of FGF23 is to promote phosphaturia, therefore, it seems logical that $\mathrm{P}$ should have a predominant effect on FGF23. The effect of acidosis on plasma P is controversial; plasma P has been reported to decrease in short-term studies carried out in healthy individuals [31] and to increase in renal patients with chronic metabolic acidosis [17]. In the course of acidosis, $P$ is extracted from bone [32] and from soft tissues [33]. Moreover, intestinal absorption of $\mathrm{P}$ is also increased during acidosis [34]. All these factors are likely responsible for the increase in plasma P detected in our acidotic rats with reduced renal function; however, the elevated plasma $\mathrm{P}$ does not explain the 
decrease in FGF23. An increase in the urinary excretion of $\mathrm{P}$ and $\mathrm{Ca}$, which is likely related to mineral extraction from bone [32], was found in acidotic rats. Acidosis has also been reported to increase phosphaturia by down-regulation of $\mathrm{Na} / \mathrm{P}$ cotransporters $\mathrm{Na} / \mathrm{Pi} 2 \mathrm{a}$ and $\mathrm{Na} / \mathrm{Pi} 2 \mathrm{c}$, in a process that seems dependent on the availability of $\mathrm{P}[35,36]$. However, more recent data have questioned the role of down-regulation of protein expression of $\mathrm{Na} / \mathrm{P}$ cotransporters and attributes the increased phosphaturia to reduced transporter activity after the interaction of protons with $\mathrm{Na} / \mathrm{Pi} 2 \mathrm{a}$ and $\mathrm{Na} / \mathrm{Pi} 2 \mathrm{c}$ [37]. It is interesting to note that acidotic rats had increased phosphaturia even though FGF23 and PTH levels were decreased. Mechanistically, it would make sense to decrease FGF23 secretion in a situation in which phosphaturia is already increased by acidosis.

Calcitriol also regulates FGF23 synthesis [12] and the stimulatory effect of calcitriol on FGF23 has been demonstrated both in healthy bone and in bone from CKD patients [38]. Metabolic acidosis is known to inhibit CYP27B1, the main enzyme that participates in calcitriol synthesis [39], although the influence of acidosis on circulating levels of vitamin metabolites D is controversial [31]. In our rats with acidosis, there was a tendency to decreased calcitriol, which may have played an additional role in the decrease in FGF23. However, the almost null correlation between calcitriol and FGF23 does not support a major influence of calcitriol on acidosis-induced FGF23 down-regulation.

PTH is another main regulator of FGF23. FGF23 concentrations have been reported to be reduced in parathyroidectomized rats, and PTH supplementation increases plasma FGF23 in a dose-dependent manner [13]. The effect of PTH on FGF23 is partially mediated by calcitriol, but PTH is able to increase FGF23 under conditions in which calcitriol is controlled [13]. Metabolic acidosis has been shown to stimulate PTH secretion [30]; however, this only occurs when plasma ionized calcium levels are clamped. In fact, the increase in ionized calcium secondary to acidosis can revert the changes in PTH [40]. The acidotic rats of the present study showed increased plasma $\mathrm{Ca}^{2+}$ concentrations, which were likely due to two mechanisms: (a) acidosis-induced mobilization of Ca from bone; and (b) acidosisinduced increase in the ionized fraction of $\mathrm{Ca}$ (by shifting the equilibrium between proteinbound and ionized $\mathrm{Ca}$ ). In agreement with the increased $\mathrm{Ca}^{2+}$, in our study, plasma PTH was consistently decreased in acidotic rats. In addition, an excellent correlation was found between plasma concentrations of PTH and FGF23. Moreover, when PTH was eliminated (in PTX rats), FGF23 did not decrease in response to acidosis. It is also interesting to note that diet-induced acidosis lowers PTH response in experimental models [41]. Thus, it is likely that changes in PTH may play a major role in the decrease in FGF23 observed in acidotic rats.

The mechanisms involved in the reduction of FGF23 induced by increased acid intake are depicted in Figure 6. In the context of acidosis, calcium and phosphate are released from bone to buffer the acid load and are abundantly excreted in the urine. The increase in $\mathrm{Ca}^{2+}$ inhibits PTH secretion, which in turn down-regulates FGF23. The decrease in FGF23 makes sense from a regulatory perspective: in the first place, because it is not needed to increase phosphaturia (which is already stimulated by acidosis), and also because of its collateral effects on calcitriol and PTH. A decrease in FGF23 will prevent a further decrease in calcitriol concentrations and will also contribute to avoiding increases in $\mathrm{PTH}$, which could be detrimental for a bone tissue already subjected to the decalcifying influence of acidosis.

Both increased FGF23 and lowered bicarbonate concentrations are considered factors that increase cardiovascular morbidity/mortality [17,42]. In fact, bicarbonate (and other alkali producing foods, like fruits and vegetables) are advocated as therapeutic strategies to reduce cardiovascular risk, particularly in patients with CKD [43]. Since bicarbonate treatment is likely to increase FGF23, it would be interesting to investigate the balance point between acid-base status and FGF23 concentrations that would be more favorable for the cardiovascular system.

In addition to traditional factors related to mineral metabolism and renal disease, there is some evidence that acidosis may influence energy metabolism. Acidosis may impair 
glycemic control and promote insulin resistance [44]. Insulin has been shown to decrease FGF23 secretion by bone cells [25]. At present, it is unclear whether acidosis-induced insulin resistance may influence the reduction of FGF23 observed in acidotic rats.

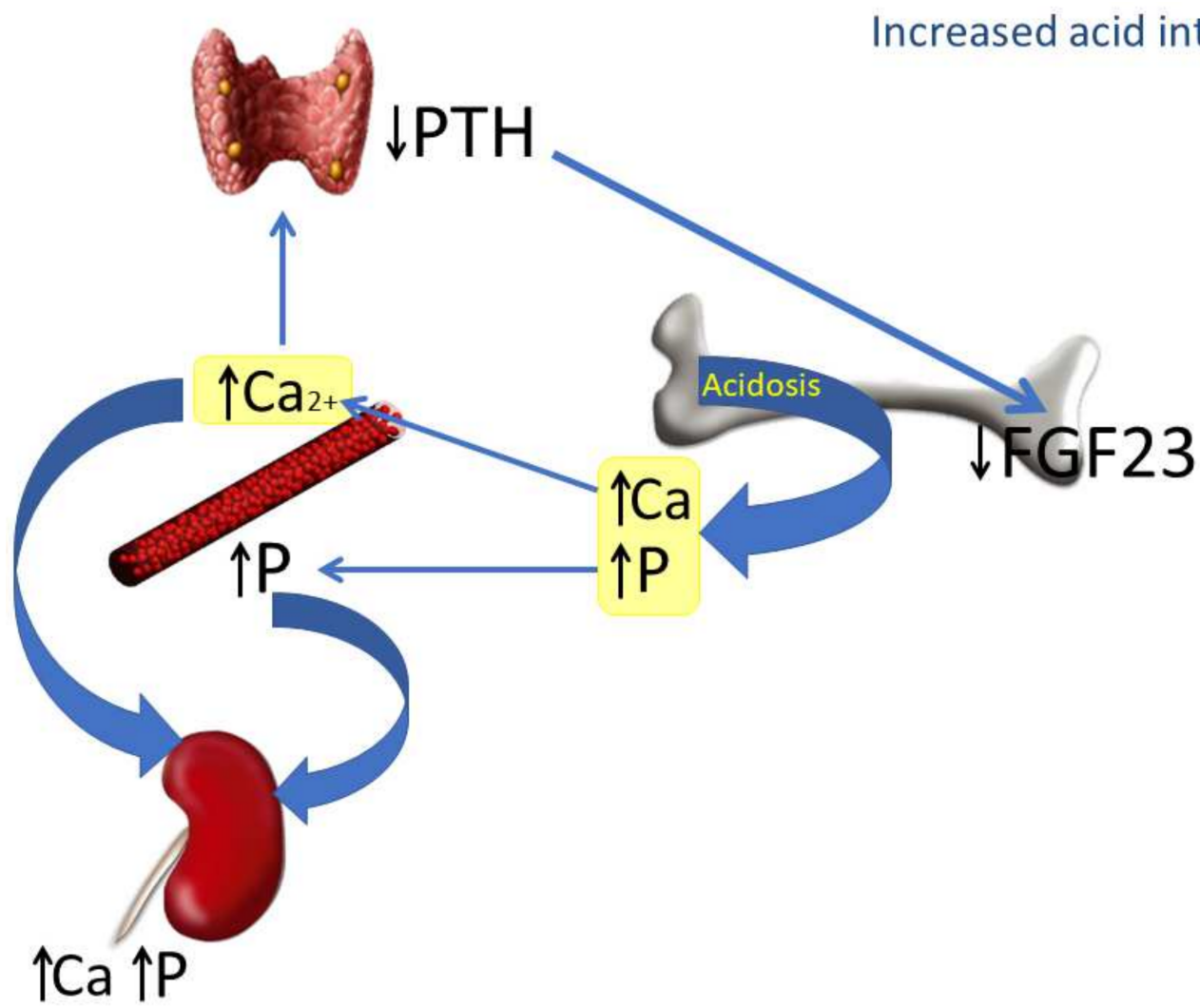

Figure 6. Proposed model integrating the actions of chronic metabolic acidosis on bone, kidney and parathyroid glands. As a consequence of metabolic acidosis, calcium (Ca) and phosphate (P) are extracted from bone. This contributes to elevating calcemia and phosphatemia and increasing urinary excretion of both $\mathrm{Ca}$ and $\mathrm{P}$. The increase in plasma $\mathrm{Ca}^{2+}$, which is further potentiated by acidosis, inhibits PTH secretion by parathyroid glands and down-regulates FGF23 production by bone cells.

This paper has some strengths and also some limitations. The main strength is the use of different animal models which allow the evaluation of the FGF23 response to acidosis in a variety of clinically relevant settings. Limitations include the fact that the results need to be confirmed in humans. The discrepancy between the in vivo and in vitro effect of acidosis on FGF23 secretion needs to be further explored. Although the influence of PTH on the acidosis-induced decrease in FGF23 seems clear, additional factors may also be playing a role in this process.

\section{Conclusions}

In conclusion, in rats with increased acid intake, plasma concentrations of FGF23 are consistently decreased, both in animals with intact renal function and with decreased renal function. The in vivo effect of metabolic acidosis on FGF23 appears to be related to the simultaneous decrease in PTH, which is secondary to an elevation of plasma $\mathrm{Ca}^{2+}$ concentration.

Supplementary Materials: The following supporting information can be downloaded at: https:/ /www. mdpi.com/article/10.3390/nu14051041/s1, Figure S1: Experimental design. Figure S2: Correlation between plasma concentrations of carboxy-terminal fibroblast growth factor 23 (cFGF23) and: (a) plasma phosphate, $\mathrm{P}$, (b) plasma parathyroid hormone, $\mathrm{PTH}$, and (c) plasma calcitriol, CTR, concentrations. Table S1: Sequences of the primers used for real-time RT-PCR. Table S2: Food, calcium (Ca) and phosphorus $(\mathrm{P})$ intake in the six experimental groups at the end of the experiment. 


\begin{abstract}
Author Contributions: Conceptualization, E.A.-T. and I.L.; methodology, E.A.-T. and I.L.; formal analysis, A.V., A.I.R. and M.R.; investigation, A.V., C.P., A.I.R., R.R., A.E., J.R.M.-C. and I.L.; writingoriginal draft preparation, A.V. and E.A.-T.; writing-review and editing, A.V., C.P., A.I.R., R.R., A.E., J.R.M.-C., M.R., E.A.-T. and I.L.; supervision, E.A.-T.; project administration, E.A-T.; funding acquisition, E.A.-T. All authors have read and agreed to the published version of the manuscript.
\end{abstract}

Funding: This research was funded by a Spanish Government Grant from the Instituto de Salud Carlos III, grant numbers PI17/00169 and PI21/00269 (Co-funded by FEDER, European Regional Development Fund; "A way to make Europe" /"Investing in your future").

Institutional Review Board Statement: The animal study protocol was approved by the Ethics Committee for Animal Research of the University of Cordoba and by Junta de Andalucia (Spain) (Ethical Code Number 30/10/2017/148, date 8 November 2017).

Informed Consent Statement: Not applicable.

Data Availability Statement: The datasets generated during and/or analyzed during the current study are available from the corresponding author on reasonable request.

Conflicts of Interest: The authors declare no conflict of interest. The funders had no role in the design of the study; in the collection, analyses, or interpretation of data; in the writing of the manuscript, or in the decision to publish the results.

\title{
References
}

1. Osuna-Padilla, I.A.; Leal-Escobar, G.; Garza-García, C.A.; Rodríguez-Castellanos, F.E. Dietary Acid Load: Mechanisms and evidence of its health repercussions. Nefrologia 2019, 39, 343-354. [CrossRef] [PubMed]

2. Kraut, J.A.; Kurtz, I. Metabolic Acidosis of CKD: Diagnosis, Clinical Characteristics, and Treatment. Am. J. Kidney Dis. 2005, 45, 978-993. [CrossRef]

3. Bürki, R.; Mohebbi, N.; Bettoni, C.; Wang, X.; Serra, A.L.; Wagner, C.A. Impaired expression of key molecules of ammoniagenesis underlies renal acidosis in a rat model of chronic kidney disease. Nephrol. Dial. Transplant. 2014, 30, 770-781. [CrossRef]

4. Raphael, K.L. Metabolic Acidosis in CKD: Core Curriculum 2019. Am. J. Kidney Dis. 2019, 74, 263-275. [CrossRef] [PubMed]

5. Chen, W.; Levy, D.S.; Abramowitz, M.K. Acid Base Balance and Progression of Kidney Disease. Semin. Nephrol. $2019,39,406-417$. [CrossRef] [PubMed]

6. Kovesdy, C.P.; Anderson, J.E.; Kalantar-Zadeh, K. Association of serum bicarbonate levels with mortality in patients with non-dialysis-dependent CKD. Nephrol. Dial. Transplant. 2008, 24, 1232-1237. [CrossRef] [PubMed]

7. Vervloet, M. Renal and extrarenal effects of fibroblast growth factor 23. Nat. Rev. Nephrol. 2018, 15, 109-120. [CrossRef]

8. Shimada, T.; Hasegawa, H.; Yamazaki, Y.; Muto, T.; Hino, R.; Takeuchi, Y.; Fujita, T.; Nakahara, K.; Fukumoto, S.; Yamashita, T. FGF-23 Is a Potent Regulator of Vitamin D Metabolism and Phosphate Homeostasis. J. Bone Miner. Res. 2004, 19, $429-435$. [CrossRef]

9. Ferrari, S.L.; Bonjour, J.-P.; Rizzoli, R. Fibroblast Growth Factor-23 Relationship to Dietary Phosphate and Renal Phosphate Handling in Healthy Young Men. J. Clin. Endocrinol. Metab. 2005, 90, 1519-1524. [CrossRef]

10. Vervloet, M.G.; Van Ittersum, F.J.; Büttler, R.M.; Heijboer, A.; Blankenstein, M.; Ter Wee, P.M. Effects of Dietary Phosphate and Calcium Intake on Fibroblast Growth Factor-23. Clin. J. Am. Soc. Nephrol. 2010, 6, 383-389. [CrossRef]

11. Masuyama, R.; Stockmans, I.; Torrekens, S.; Van Looveren, R.; Maes, C.; Carmeliet, P.; Bouillon, R.; Carmeliet, G. Vitamin D receptor in chondrocytes promotes osteoclastogenesis and regulates FGF23 production in osteoblasts. J. Clin. Investig. 2006, 116, 3150-3159. [CrossRef] [PubMed]

12. Collins, M.T.; Lindsay, J.R.; Jain, A.; Kelly, M.H.; Cutler, C.M.; Weinstein, L.S.; Liu, J.; Fedarko, N.S.; Winer, K.K. Fibroblast Growth

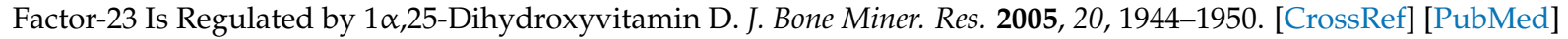

13. López, I.; Rodríguez-Ortiz, M.E.; Almadén, Y.; Guerrero, F.; de Oca, A.M.; Pineda, C.; Shalhoub, V.; Rodriguez, M.; Aguilera-Tejero, E. Direct and indirect effects of parathyroid hormone on circulating levels of fibroblast growth factor 23 in vivo. Kidney Int. 2011, 80, 475-482. [CrossRef] [PubMed]

14. David, V.; Martin, A.; Isakova, T.; Spaulding, C.; Qi, L.; Ramirez, V.; Zumbrennen-Bullough, K.B.; Sun, C.C.; Lin, H.Y.; Babitt, J.L.; et al. Inflammation and functional iron deficiency regulate fibroblast growth factor 23 production. Kidney Int. 2016, 89, 135-146. [CrossRef] [PubMed]

15. Bożentowicz-Wikarek, M.; Kocełak, P.; Owczarek, A.; Olszanecka-Glinianowicz, M.; Mossakowska, M.; Skalska, A.; Więcek, A.; Chudek, J. Plasma fibroblast growth factor 23 concentration and iron status. Does the relationship exist in the elderly population? Clin. Biochem. 2015, 48, 431-436. [CrossRef]

16. Vidal, A.; Rios, R.; Pineda, C.; Lopez, I.; Muñoz-Castañeda, J.R.; Rodriguez, M.; Aguilera-Tejero, E.; Raya, A.I. Direct regulation of fibroblast growth factor 23 by energy intake through mTOR. Sci. Rep. 2020, 10, 1795. [CrossRef]

17. Scialla, J.J.; Xie, H.; Rahman, M.; Anderson, A.H.; Isakova, T.; Ojo, A.; Zhang, X.; Nessel, L.; Hamano, T.; Grunwald, J.E.; et al. Fibroblast Growth Factor-23 and Cardiovascular Events in CKD. J. Am. Soc. Nephrol. 2014, 25, 349-360. [CrossRef] 
18. Kestenbaum, B.; Sachs, M.C.; Hoofnagle, A.N.; Siscovick, D.S.; Ix, J.H.; Robinson-Cohen, C.; Lima, J.A.; Polak, J.F.; Blondon, M.; Ruzinski, J.; et al. Fibroblast Growth Factor-23 and Cardiovascular Disease in the General Population. Circ. Heart Fail. 2014, 7, 409-417. [CrossRef]

19. Panwar, B.; Jenny, N.S.; Howard, V.J.; Wadley, V.G.; Muntner, P.; Kissela, B.M.; Judd, S.E.; Gutiérrez, O.M. Fibroblast Growth Factor 23 and Risk of Incident Stroke in Community-Living Adults. Stroke 2015, 46, 322-328. [CrossRef]

20. Krieger, N.S.; Culbertson, C.D.; Kyker-Snowman, K.; Bushinsky, D.A. Metabolic acidosis increases fibroblast growth factor 23 in neonatal mouse bone. Am. J. Physiol. Physiol. 2012, 303, F431-F436. [CrossRef]

21. Krieger, N.S.; Bushinsky, D.A. Stimulation of fibroblast growth factor 23 by metabolic acidosis requires osteoblastic intracellular calcium signaling and prostaglandin synthesis. Am. J. Physiol. Physiol. 2017, 313, F882-F886. [CrossRef]

22. Leibrock, C.B.; Alesutan, I.; Voelkl, J.; Pakladok, T.; Michael, D.; Schleicher, E.; Kamyabi-Moghaddam, Z.; Quintanilla-Martinez, L.; Kuro-O, M.; Lang, F. NH4Cl Treatment Prevents Tissue Calcification in Klotho Deficiency. J. Am. Soc. Nephrol. 2015, 26, $2423-2433$. [CrossRef]

23. Chen, W.; Melamed, M.L.; Hostetter, T.H.; Bauer, C.; Raff, A.C.; Almudevar, A.L.; LaLonde, A.; Messing, S.; Abramowitz, M.K. Effect of oral sodium bicarbonate on fibroblast growth factor-23 in patients with chronic kidney disease: A pilot study. BMC Nephrol. 2016, 17, 114. [CrossRef] [PubMed]

24. Khairallah, P.; Isakova, T.; Asplin, J.; Hamm, L.; Dobre, M.; Rahman, M.; Sharma, K.; Leonard, M.; Miller, E.; Jaar, B.; et al. Acid Load and Phosphorus Homeostasis in CKD. Am. J. Kidney Dis. 2017, 70, 541-550. [CrossRef] [PubMed]

25. Bär, L.; Feger, M.; Fajol, A.; Klotz, L.-O.; Zeng, S.; Lang, F.; Hocher, B.; Föller, M. Insulin suppresses the production of fibroblast growth factor 23 (FGF23). Proc. Natl. Acad. Sci. 2018, 115, 5804-5809. [CrossRef]

26. Raya, A.I.; Rios, R.; Pineda, C.; Rodriguez-Ortiz, M.E.; Diez, E.; Almaden, Y.; Muñoz-Castañeda, J.R.; Rodriguez, M.; Aguilera-Tejero, E.; Lopez, I. Energy-dense diets increase FGF23, lead to phosphorus retention and promote vascular calcifications in rats. Sci. Rep. 2016, 6, 36881. [CrossRef] [PubMed]

27. Hanifa, M.A.; Skott, M.; Maltesen, R.G.; Rasmussen, B.S.; Nielsen, S.; Frøkiær, J.; Ring, T.; Wimmer, R. Tissue, urine and blood metabolite signatures of chronic kidney disease in the 5/6 nephrectomy rat model. Metabolomics 2019, 15, 1-16. [CrossRef]

28. Jara, A.; Felsenfeld, A.J.; Bover, J.; Kleeman, C.R. Chronic metabolic acidosis in azotemic rats on a high-phosphate diet halts the progression of renal disease. Kidney Int. 2000, 58, 1023-1032. [CrossRef] [PubMed]

29. Alber, J.; Föller, M. Lactic acid induces fibroblast growth factor 23 (FGF23) production in UMR106 osteoblast-like cells. Mol. Cell. Biochem. 2021, 477, 363-370. [CrossRef]

30. Lopez, I.; Aguilera-Tejero, E.; Felsenfeld, A.J.; Estepa, J.C.; Rodriguez, M. Direct Effect of Acute Metabolic and Respiratory Acidosis on Parathyroid Hormone Secretion in the Dog. J. Bone Miner. Res. 2002, 17, 1691-1700. [CrossRef]

31. Krapf, R.; Vetsch, R.; Vetsch, W.; Hulter, H.N. Chronic metabolic acidosis increases the serum concentration of 1,25dihydroxyvitamin $\mathrm{D}$ in humans by stimulating its production rate. Critical role of acidosis-induced renal hypophosphatemia. J. Clin. Investig. 1992, 90, 2456-2463. [CrossRef]

32. Bushinsky, D.A.; Frick, K.K. The effects of acid on bone. Curr. Opin. Nephrol. Hypertens. 2000, 9, 369-379. [CrossRef] [PubMed]

33. Lemann, J.; Litzow, J.R.; Lennon, E.J. The effects of chronic acid loads in normal man: Further evidence for the participation of bone mineral in the defense against chronic metabolic acidosis. J. Clin. Investig. 1966, 45, 1608-1614. [CrossRef]

34. Stauber, A.; Radanovic, T.; Stange, G.; Murer, H.; Wagner, C.A.; Biber, J. Regulation of Intestinal Phosphate Transport II. Metabolic acidosis stimulates $\mathrm{Na}^{+}$-dependent phosphate absorption and expression of the $\mathrm{Na}^{+}-\mathrm{Pi}$ cotransporter $\mathrm{NaPi}-\mathrm{IIl}$ in small intestine. Am. J. Physiol. Liver Physiol. 2005, 288, G501-G506. [CrossRef] [PubMed]

35. Ambühl, P.M.; Zajicek, H.K.; Wang, H.; Puttaparthi, K.; Levi, M.; Wilson, W.T.T.A.O.P. Regulation of renal phosphate transport by acute and chronic metabolic acidosis in the rat. Kidney Int. 1998, 53, 1288-1298. [CrossRef]

36. Nowik, M.; Lecca, M.R.; Velic, A.; Rehrauer, H.; Brändli, A.W.; Wagner, C.A. Genome-wide gene expression profiling reveals renal genes regulated during metabolic acidosis. Physiol. Genom. 2008, 32, 322-334. [CrossRef] [PubMed]

37. Nowik, M.; Picard, N.; Stange, G.; Capuano, P.; Tenenhouse, H.S.; Biber, J.; Murer, H.; Wagner, C.A. Renal phosphaturia during metabolic acidosis revisited: Molecular mechanisms for decreased renal phosphate reabsorption. Pflügers Arch.-Eur. J. Physiol. 2008, 457, 539-549. [CrossRef] [PubMed]

38. Pereira, R.C.; Salusky, I.B.; Bowen, R.E.; Freymiller, E.G.; Wesseling-Perry, K. Vitamin D sterols increase FGF23 expression by stimulating osteoblast and osteocyte maturation in CKD bone. Bone 2019, 127, 626-634. [CrossRef] [PubMed]

39. Kawashima, H.; Kraut, J.A.; Kurokawa, K. Metabolic Acidosis Suppresses 25-Hydroxyvitamin D3-1 $\alpha$-Hydroxylase in the Rat Kidney. Distinct site and mechanism of action. J. Clin. Investig. 1982, 70, 135-140. [CrossRef]

40. Lopez, I.; Aguilera-Tejero, E.; Estepa, J.C.; Rodriguez, M.; Felsenfeld, A.J. Role of acidosis-induced increases in calcium on PTH secretion in acute metabolic and respiratory acidosis in the dog. Am. J. Physiol. Metab. 2004, 286, E780-E785. [CrossRef]

41. Della Guardia, L.; Thomas, M.A.; Cena, H. Insulin Sensitivity and Glucose Homeostasis Can Be Influenced by Metabolic Acid Load. Nutrients 2018, 10, 618. [CrossRef]

42. Wesson, D.E. Serum bicarbonate as a cardiovascular risk factor: Evolving from 'non-traditional'? Nephrol. Dial. Transplant. 2020, 35, 1282-1285. [CrossRef] [PubMed] 
43. Goraya, N.; Munoz-Maldonado, Y.; Simoni, J.; Wesson, D.E. Fruit and Vegetable Treatment of Chronic Kidney Disease-Related Metabolic Acidosis Reduces Cardiovascular Risk Better than Sodium Bicarbonate. Am. J. Nephrol. 2019, 49, 438-448. [CrossRef] [PubMed]

44. Della Guardia, L.; Roggi, C.; Cena, H. Diet-induced acidosis and alkali supplementation. Int. J. Food Sci. Nutr. 2016, 67, 754-761. [CrossRef] [PubMed] 